Informe especial

\title{
Haplotipos de la hemoglobina S: importancia epidemiológica, antropológica y clínica
}

\author{
Walter E. Rodríguez Romero, ${ }^{1}$ Germán F. Sáenz Renauld ${ }^{1}$ \\ y Mario A. Chaves Villalobos ${ }^{1}$
}

RESUMEN La relación entre la drepanocitosis y los diferentes haplotipos del gen que codifica la subunidad $\beta^{s}$ de la globina ha permitido llegar a entender mejor las manifestaciones clínicas de aquella enfermedad. El uso de mejores técnicas de laboratorio permite descartar la presencia de otros factores hereditarios capaces de ocultar el verdadero genotipo hemoglobinico. La heterogeneidad clínica de la drepanocitosis, afección caracterizada por la presencia de una hemoglobina anormal denominada $\mathrm{HbS}$, depende de las concentraciones de hemoglobina fetal ( $\mathrm{HbF}$ ), la razón de cadenas $G \gamma$ a cadenas Ay en la molécula de globina, las concentraciones de 2,3difosfoglicerato, la presencia de mutaciones ligadas, los haplotipos del gen $\beta^{s}$, la presencia simultánea de $\alpha$-talasemia, y factores ambientales. En particular, los polimorfismos Senegal y árabe-saudí o indio del conglomerado de genes que codifican la subunidad $\beta^{s}$ se asocian con una evolución clínica menos grave, mientras que los haplotipos de la República Centroafricana (CAR) o Bantú, Camerún y Benín se asocian con drepanocitosis grave. De todos, el haplotipo

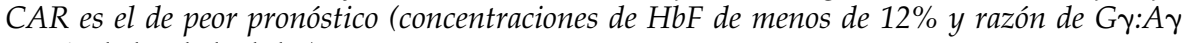
propia de la edad adulta).

Estos polimorfismos del ácido desoxirribonucleico, una vez caracterizados, adquieren enorme importancia como marcadores antropológicos y genéticos. En las Américas, los haplotipos $\beta^{s}$ permiten entender mejor las raíces ancestrales africanas de las poblaciones de raza negra. Se ha comprobado la presencia de variedad genética no solo entre las diferentes poblaciones negras de las Américas, sino también dentro de un mismo país, como se observa en Costa Rica.

Las hemoglobinas anormales $\mathrm{S}$ y $\mathrm{C}$ $(\mathrm{HbS}$ y $\mathrm{HbC})$, que prevalecen en el África y partes de Europa y las Américas, y la hemoglobina $\mathrm{E}(\mathrm{HbE})$, que es más común en Asia Sudoriental, son responsables de diversos trastornos y

\footnotetext{
1 Universidad de Costa Rica, Facultad de Microbiología, San José, Costa Rica. Toda correspondencia debe dirigirse a W. E. Rodríguez Romero a la siguiente dirección postal: Centro de Investigación en Hemoglobinas Anormales y Trastornos Afines (CIHATA), Departamento de Análisis Clínicos, Facultad de Microbiología, Universidad de Costa Rica, San José, Costa Rica. Correo electrónico: werodrig@cariari.ucr.ac.cr
}

de tasas de mortalidad elevadas, ya que constituyen variantes funcionalmente anormales de la hemoglobina A $(\mathrm{HbA})(1,2)$. La importancia de las hemoglobinopatías en el ámbito de la salud pública ha suscitado un acelerado desarrollo de tecnologías para su análisis en el laboratorio, particularmente de procedimientos diagnósticos rápidos y precisos. Entre ellos figuran algunos métodos que permiten detectar directamente el trastorno genómico asociado con cada una de las diferentes alteraciones moleculares de $\mathrm{la} \mathrm{Hb}$
(3-5). Estos avances vertiginosos han ayudado a dilucidar patrones electroforéticos convencionales que otrora confundían el diagnóstico clínico, así como a clasificar perfiles hereditarios complejos y a investigar diversas poblaciones humanas desplazadas a nuevos continentes. Tal es el caso de los haplotipos o segmentos de restricción polimórficos o de longitud variable del ácido desoxirribonucleico (ADN), cuya caracterización ha permitido descifrar los mosaicos culturales y étnicos de ciertas poblaciones y explicar, al menos 
parcialmente, la heterogeneidad clínica de la drepanocitosis, conocida también por anemia de células falciformes $(6-8)$.

\section{HAPLOTIPOS LIGADOS AL GEN $\beta^{S}$ Y POLIMORFISMOS GENETICOS EQUILIBRADOS}

El análisis del ADN de diversos individuos en distintas poblaciones ha puesto de manifiesto que existen mutaciones productoras de polipéptidos cuya secuencia de aminoácidos está alterada (por ejemplo, variantes de la $\mathrm{Hb})$, y también diferencias en las secuencias nucleotídicas que no alteran la función del gen. Estas variantes "silenciosas" se definen como polimorfismos del ADN. Se ha calculado que aproximadamente una de cada 100 bases es polimórfica -ello significa que en esa posición puede haber nucleótidos distintos- y se ha demostrado que estas variaciones se presentan casi exclusivamente en las regiones adyacentes a los genes y en los intrones, mientras que las secuencias de los exones se mantienen prácticamente constantes. La presencia o ausencia del sitio polimórfico produce los llamados fragmentos de restricción de longitud variable (en inglés, restriction fragment length polymorphisms, o RFLP). Ciertas enzimas "cortadoras" (cleavage enzymes) tienen afinidad exclusiva por los distintos puntos polimórficos en la cadena de ADN y por lo tanto se usan para dividirla en sus diferentes RFLP (9).

Se han descrito polimorfismos "públicos" que son comunes a todos los grupos étnicos y otros denominados "privados" que son característicos de una raza determinada. Cuando se habla de haplotipos se hace alusión a los diversos patrones o fragmentos polimórficos de ADN a lo largo de una misma región cromosómica. Se desprende que diferentes combinaciones de sitios polimórficos constituyen los llamados haplotipos y que dichas combinaciones pueden ser útiles para detectar cualquier mutación que se encuentre asociada con un haplotipo en particular, es decir, que esté siempre presente en un cromosoma carac- terizado por un haplotipo específico. En cada grupo étnico se puede encontrar una asociación específica entre un haplotipo en particular y una mutación determinada. Cuando ello ocurre, se dice que la mutación está en desequilibrio de asociación (linkage disequilibrium) con un haplotipo específico. Cabe destacar que la presencia de esta asociación no significa que un haplotipo en particular siempre esté ligado a determinada mutación. Más bien, el mismo haplotipo se puede detectar en individuos normales de la misma población, lo cual indica simplemente que la mutación ocurrió en un cromosoma caracterizado por ese haplotipo y, en la mayoría de los casos, sugiere que se encuentra con frecuencia en esa población (9).

El estudio de los haplotipos ha sido especialmente útil para detectar diferencias genéticas entre los alelos de globina presentes en diferentes mutaciones que codifican alteraciones de la síntesis de la molécula de $\mathrm{Hb}$. En el caso del gen de la globina $\beta$, los segmentos polimórficos se ubican en el brazo largo del cromosoma 11 (6) en las regiones flanqueadoras del gen (10, 11). Desde la primera descripción de estos fragmentos por Kan y Dozy (10) se han encontrado seis haplotipos mayores o principales y varios haplotipos menores, todos coheredados con la mutación $\beta^{\text {s }}$ como alelos sencillos, demostrándose con ello sus orígenes en zonas específicas de África y Asia. Los seis mayores se denominan, en consecuencia, haplotipos Benín (Ben); República Centroafricana (CAR) o Bantú; Senegal (Sen); Camerún (Cam); árabe-saudí, y asiático (indio) $(11,12)$.

Cada haplotipo presenta patrones de restricción característicos, siendo mínimas las diferencias moleculares entre algunos de ellos. Tal es el caso de los haplotipos árabe-saudí y asiático: el primero presenta en la posición 81 del intrón II una molécula de citosina (C) y el segundo una timina ( $\mathrm{T})$, y en el nucleótido 101 de la región flanqueadora se observa una guanina $(G)$ en el haplotipo árabe-saudí y una $C$ en el haplotipo asiático (7-13). La caracterización de los cuatro haplotipos africanos principales y su relación directa con zonas geográficas determinadas se han esgrimido como argumento a favor de la teoría de que la mutación $\beta^{\mathrm{s}}$ tuvo un origen multicéntrico en el continente africano (14-16), noción que ha desplazado a la teoría unicéntrica que prevaleció por muchos años (17).

La aparición del gen $\beta^{\mathrm{s}}$ está estrechamente ligada a la evolución misma del ser humano. Se sabe, por ende, que Australopithecus ramidius, el antecesor más primitivo del hombre y el más recientemente descrito, data de hace alrededor de 4,4 millones de años, mientras que la especie que le sigue en la escala evolutiva, Australopithecus aferensis, tiene una edad estimada de cerca de 3,2 millones de años (18). Se cree que la evolución de los genes de la $\mathrm{Hb}$ humana es aun más antigua y que todos los genes de globina se originaron posiblemente en un gen que codificaba una proteína común, similar a la asociada con el grupo hem en la molécula de hemoglobina (19). La divergencia más antigua de este gen primitivo hace alrededor de 700 millones de años llevó a la diferenciación entre la mioglobina y la hemoglobina $(\mathrm{Hb})(19$, 20). Otra divergencia posterior dio origen a la separación de los genes de las globinas $\alpha$ y $\beta$ hace aproximadamente 450 millones de años. A partir del gen $\beta$ se desarrollaron dos genes ancestrales, uno para las globinas $\gamma$ y $\in$ y otro para las globinas $\delta$ y $\beta$ (hace 200 millones de años). El gen ancestral $\epsilon / \gamma$ evolucionó hace alrededor de 110 millones de años hacia los actuales genes individuales. Finalmente, la separación más reciente de los genes de $\mathrm{Hb}$ tuvo lugar en el período que transcurrió hace 85 a 100 millones de años y culminó con la segregación de los genes $\beta$ y $\delta$ (19).

Los datos obtenidos hasta la fecha sugieren que la aparición de la mutación $\beta^{\text {s }}$ es mucho más reciente, quizá de hace 30000 años, debido a su estrecha relación con el inicio del sedentarismo humano (20). Desde un punto de vista antropológico y epidemiológico, parece evidente que en el caso de la hemoglobina anormal de la drepanocitosis (HbS), así como en el de otras variantes comunes de la $\mathrm{Hb}$ clínicamente importantes, la selección fue una respuesta natural a la presión 
entonces ejercida por la malaria (20). Esta mutación se convirtió en un importante factor selectivo a partir del momento en que se inició un contacto estrecho entre el huésped humano, el parásito y el vector. Mientras el ser humano primitivo tuvo en la cacería y la vida nómada sus principales actividades y la densidad poblacional se mantuvo en escasamente una persona por $29,7 \mathrm{~km}^{2}$, la malaria no adquirió carácter holoendémico (transmisión continua e invariable durante todo el año) (20), pero cuando se desarrolló la agricultura y con ella aparecieron los primeros asentamientos humanos, la malaria se convirtió en un factor selectivo muy importante. La mayor densidad poblacional, la destrucción o alejamiento de otros huéspedes mamíferos y la adaptación del mosquito vector a las poblaciones humanas fueron hechos decisivos para la consolidación de la malaria endémica y la endemicidad del gen $\beta^{\text {s }}$ (20).

La $\mathrm{HbS}$ se encuentra distribuida de manera bastante uniforme en el continente africano. No obstante, su frecuencia disminuye bruscamente en el África meridional (6). Esta aparente contradicción se explica, en primer lugar, por el hecho de que el desierto de Kalaharí sirvió como barrera natural contra Plasmodium falciparum, manteniéndose las regiones situadas al sur habitualmente libres de malaria (6). Otro factor digno de consideración se asocia con el hecho de que la migración de poblaciones de habla bantú hace alrededor de 2000 años no llegó al extremo sur del continente -más adelante este punto se examinará en extenso-, limitándose por ese medio la diseminación de esta $\mathrm{Hb}$ anormal (6). La HbS es, por lo tanto, muy común en las regiones ecuatoriales subsaharianas, observándose con mayor frecuencia (en $8 \%$ a más de $25 \%$ de la población) en tres zonas principales: alrededor de los ríos de Gambia y Senegal en el África occidental del litoral atlántico; cerca de los ríos del bajo Níger y de Benín en la región occidental centroafricana; y alrededor del río Congo en el África central $(8,20)$.

El análisis de los haplotipos asociados con otras dos variantes de $\mathrm{Hb}$ muy frecuentes, la $\mathrm{HbE}$ en el Asia y la $\mathrm{HbC}$ en el África, sugiere la posibilidad de que en el primer caso la mutación haya ocurrido un mínimo de dos veces en el llamado "triángulo de $\mathrm{HbE}$ ", que comprende Tailandia, Viet Nam y Camboya $(6,21,22)$. En el segundo caso se ha demostrado un origen único de la mutación en asociación con el trastorno genético $\beta^{\mathrm{c}}$ y su posterior extensión a otros haplotipos por la vía de la recombinación meiótica de la subregión 5' al gen de la globina $\beta$. Esto confirma de manera indirecta el origen independiente de los genes $\beta^{\mathrm{c}}$ y $\beta^{\mathrm{s}}(6$, 10, 23).

\section{ASPECTOS HISTÓRICOS, ANTROPOLÓGICOS Y EPIDEMIOLÓGICOS DE LOS HAPLOTIPOS $\beta^{S}$}

La identificación en el nivel genético-molecular de los polimorfismos del gen $\beta^{\text {s }}$ ha permitido estudiar los patrones culturales y migratorios de pueblos africanos, afroamericanos y asiáticos (12). En el África, por ejemplo, se definen claramente secuencias polimórficas muy específicas en cuatro regiones: el haplotipo Sen prevalece en el África del litoral atlántico; el Ben se localiza predominantemente en el occidente centroafricano; el CAR predomina en el África central y el fragmento polimórfico Cam se circunscribe a una zona limitada de Camerún (figura 1) $(12,15,24)$.

La localización geográfica específica de estos polimorfismos del ADN es la siguiente:

Sen: Se encuentra en Senegal, Gambia, Guinea, Guinea-Bissau, Sierra Leona, Liberia y parte de la Côte d'Ivoire.

Ben: Abarca partes de la Côte d'Ivoire, Togo, Benín, Burkina Faso (Alto Volta) y el oeste de Nigeria.

CAR: Se encuentra diseminado por la zona meridional de Gabón, República Centroafricana, Congo, Zaire y Angola.

Cam: Está circunscrito al grupo étnico eton, originario del valle del río Sanaga en la zona central del Camerún.

La localización geográfica particular de estos haplotipos no se produjo al azar, sino que se derivó de patrones migratorios ancestrales bien conocidos. Se postula, a la luz de ciertos estudios antropológicos, que hace aproximadamente 4000 años todo el continente africano, a exclusión de la parte septentrional, estaba conformado por tres grandes grupos étnicos denominados negros, pigmeos y bosquimanos. Los primeros habitaban amplias zonas del África occidental; los segundos, el África ecuatorial y los últimos las partes australes del continente (6). Se cree que hace alrededor de 2000 años se iniciaron varios cambios importantes en el equilibrio étnico y cultural del continente: las tribus que conformaban el grupo de negros incrementaron notoriamente su poder $\mathrm{y}$ ello desencadenó una emigración forzada de los otros dos grupos (6). De esta manera, los pigmeos se establecieron en lugares boscosos ecuatoriales, mientras que los bosquimanos se asentaron en territorios adyacentes al gran desierto de Kalaharí. Los dos últimos grupos presentan hoy en día características lingüísticas comunes y constituyen los pueblos de habla bantú (6). Esta cadena de migraciones ocasionó una dispersión no casual de los diferentes polimorfismos del gen $\beta^{\text {s }}$, que se circunscribieron principalmente a las zonas de asentamiento de estos grupos étnicos $(6,12)$.

La dispersión geográfica del gen $\beta^{s}$ (y, por consiguiente, de sus haplotipos) no permaneció circunscrita al África, como se sabe, sino que se extendió por lo menos a partes circundantes del Mediterráneo (25). En esa zona el haplotipo más frecuente es el Ben, que llegó a Grecia y Sicilia por medio de las invasiones musulmanas y a Portugal por el tráfico de esclavos $(6,12,14$, 26-28). Los datos reunidos hasta la fecha sugieren que el gen de la $\mathrm{HbS}$ se originó en el occidente centroafricano y que se introdujo en los territorios que colindaban con el Mediterráneo mediante mecanismos de flujo genético (genetic drift) producidos por mi- 
FIGURA 1. Distribución de haplotipos del cromosoma $\beta^{\mathrm{s}}$ en el continente africano

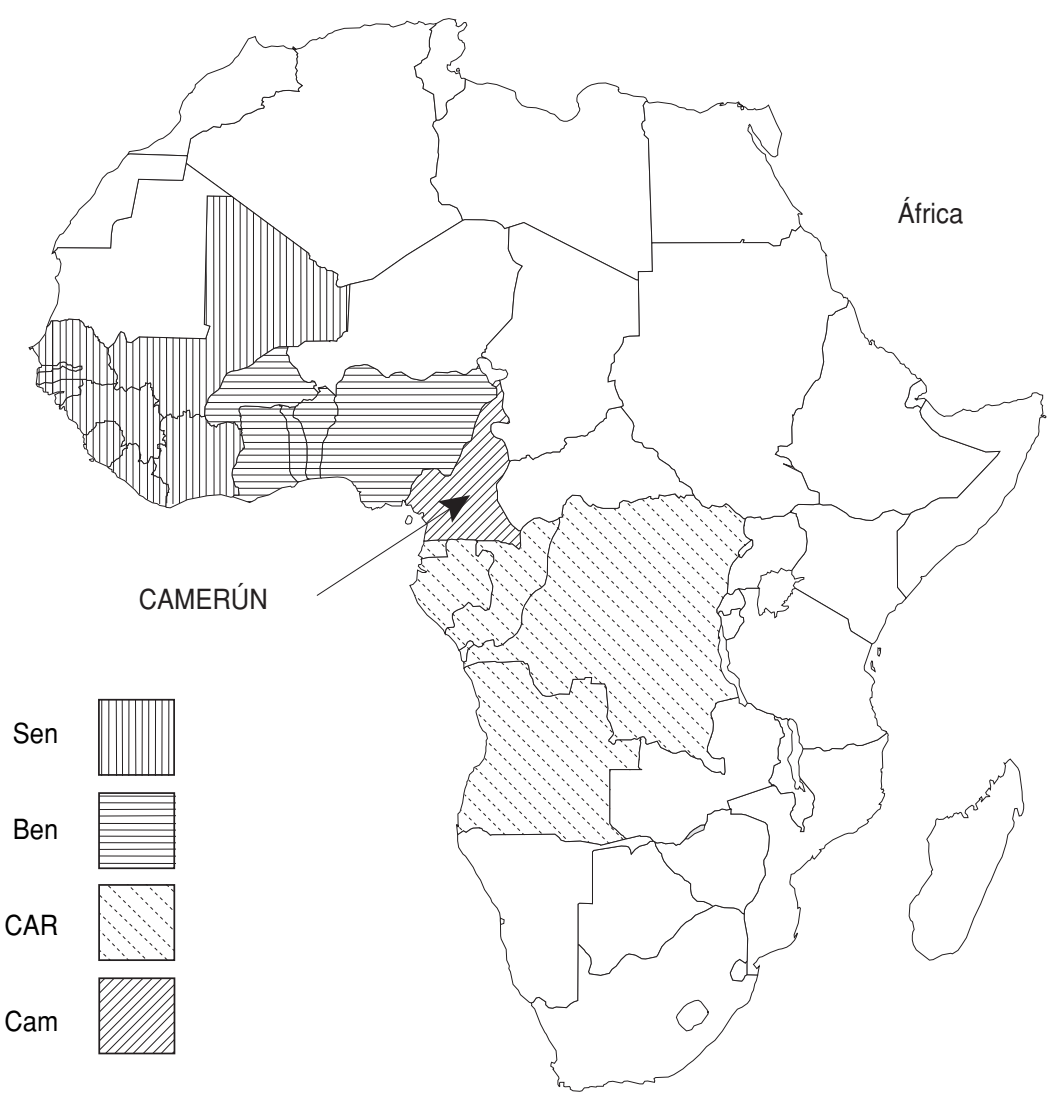

graciones a través del desierto del Sahara en el norte del África $(14,25,28)$.

Los otros haplotipos $\beta^{\mathrm{s}}$ de interés son el árabe-saudí y el indio o asiático $(27,29,30)$. Es probable que estos hayan tenido un origen distinto del de los haplotipos africanos, estando estrechamente relacionados entre sí por las corrientes migratorias que se establecieron entre territorios cercanos al río Indo (cuna de la civilización de Harappa en el subcontinente indio) y pueblos originarios del Oasis del Este en la península arábiga, y de manera más concreta entre indios, árabes chiítas e iraníes $(6,31,32)$. Fue aparentemente a orillas del río sagrado de la India donde se originó la mutación asiática de la $\mathrm{HbS}$, lo que sugiere, a diferencia de lo sucedido en el África, que el origen del gen $\beta^{s}$ en la India fue de carácter unicéntrico (32).

En las Américas, el estudio de los haplotipos $\beta^{s}$ ha contribuido a desci- frar las intrincadas aventuras del trasiego de esclavos negros del África al nuevo continente durante siglos pretéritos $(6,12)$. Es bien sabido que el flujo genético de la $\mathrm{HbS}$ a las Américas proviene exclusivamente del África, a excepción de una pequeña fracción aportada por inmigrantes europeos $(12,33,34)$. Prácticamente se acepta que las Américas, al estar libres de malaria antes de la llegada de los Europeos, estaba exenta de hemoglobinopatías. Se han realizado estudios poblacionales en territorios fuera del anillo malárico mundial -Corea, Groenlandia, Islandia, Japón, Micronesia, Polinesia y Siberia son algunos ejemplos, más algunos estudios en nativos australianos y en aborígenes americanos- y se ha determinado que prácticamente todos son homocigóticos para la $\mathrm{HbA}$, siempre y cuando sean autóctonos de la región (20). Cabe notar, como dato excepcional, que las tribus étnicamente puras de América del Sur que actualmente viven en zonas infestadas por Plasmodium también son homocigóticas para la $\mathrm{HbA}(20)$.

Como el gen de la $\mathrm{HbS}$ se encuentra distribuido amplia y heterogéneamente por todas las Américas como resultado de diferentes movimientos étnicos $(12,25)$ (cuadro 1), la capacidad de determinar las frecuencias de los polimorfismos $\beta^{\mathrm{s}}$ africanos ha llevado a historiadores y antropólogos a estudiar las raíces ancestrales de este gen anormal en las Américas. Gracias a la caracterización de cada haplotipo, se sabe que de los 75000 esclavos que llegaron a Jamaica entre 1655 y 1807, $10 \%$ provenían de países cercanos a Senegal, $72 \%$ de regiones aledañas a Benín y el $17 \%$ restante de zonas de habla bantú $(6,12)$. Se calcula que en Cuba, $42 \%$ de los africanos importados por traficantes europeos eran origina-

CUADRO 1. Prevalencia de hemoglobina S en las poblaciones negra y negroide de América Latina

\begin{tabular}{lrr}
\hline & \multicolumn{2}{c}{ Individuos } \\
\cline { 2 - 3 } \multicolumn{1}{c}{ País } & \multicolumn{1}{c}{ No. } & $\%$ \\
\hline Barbados & 912 & 7,0 \\
Belice & 724 & 27,7 \\
Brasil & 21372 & 6,2 \\
Colombia & 1184 & 11,9 \\
Costa Rica & 1830 & 8,1 \\
Cuba & 6996 & 6,1 \\
Curaçao & 2499 & 10,7 \\
Dominica & 1000 & 13,1 \\
Ecuador & 1734 & 17,8 \\
Guadalupe & 1000 & 9,2 \\
Guatemala & 150 & 18,3 \\
Haití & 807 & 13,2 \\
Honduras & 1671 & 10,0 \\
Jamaica & 100000 & 10,0 \\
Martinica & 213 & 9,4 \\
México & - & 11,2 \\
Nicaragua & 118 & 11,1 \\
Panamá & 7604 & 16,0 \\
Portugal & 1000 & 5,4 \\
Puerto Rico & 1921 & 7,1 \\
República Dominicana & 798 & 7,0 \\
San Vicente & 748 & 8,7 \\
Santa Lucía & 825 & 14,0 \\
Santo Tomás & 1769 & 9,1 \\
Suriname & 1058 & 17,1 \\
Trinidad y Tabago & 379 & 11,1 \\
Venezuela & 2132 & 8,7 \\
\hline Fuente:Reren & &
\end{tabular}

Fuente: Referencia 32. 
rios del occidente centroafricano (haplotipo Ben), 54,8\% de territorios bantúes (haplotipo CAR) y una porción insignificante de la costa occidental africana (Sen) $(6,12)$. Pese al tamaño reducido de la muestra, se puede inferir de manera preliminar a partir de ciertos informes provenientes de Centroamérica (excluida Costa Rica) que el haplotipo CAR es el predominante, lo que sugiere que la principal corriente de esclavos importados provenía de países como Gabón y Angola (12).

En Costa Rica, los resultados de estudios en las poblaciones negra $\mathrm{y}$ negroide de las costas del Atlántico y Pacífico, respectivamente, permiten comprobar diferencias ancestrales entre individuos negros de ambos territorios $(34,35)$. En la costa del Caribe (provincia de Limón) se observa un predominio del haplotipo Ben $(73,3 \%)$, reflejo del caudal de esclavos que vino del occidente centroafricano a Jamaica y de ahí a Costa Rica. Por otra parte, aunque el haplotipo Ben predomina en la provincia de Guanacaste (litoral pacífico), el haplotipo CAR se observa con mucha más frecuencia en ese territorio que en la costa atlántica (cuadro 2) (35). Estos resultados sugieren que el tráfico de esclavos africanos en el Caribe refleja lo acontecido en Jamaica y previamente en el occidente centroafricano, aunque ya con los primeros conquistadores y posteriormente en el siglo XVI se produjo alguna migración directa de la raza negra (33).

Por otra parte, la constitución genética de los grupos de raza negra de Guanacaste responde, al menos en buena medida, al similar trasiego español acaecido en Cuba, que afectó a esta zona de Centroamérica tras el exi-

CUADRO 2. Distribución porcentual de haplotipos en Costa Rica, según zona geográfica

\begin{tabular}{lcc}
\hline Haplotipo & Costa atlántica & Costa pacífica \\
\hline Sen & 20,0 & 16,6 \\
Ben & 73,3 & 58,3 \\
CAR & 6,7 & 25,0 \\
\hline
\end{tabular}

Fuente: Referencia 34. lio del caudillo cubano Antonio Maceo y de centenares de sus compatriotas a finales del siglo pasado. También es cierto que esta última zona del Pacífico recibió el influjo migratorio de negros procedentes de Panamá y Nicaragua, así como de los esclavos que acompañaron a los conquistadores españoles en los albores de la colonia, factores que pueden contribuir a aclarar las diferencias étnicas entre ambas costas $(34,35)$. Todo ello sugiere, cuando se suma a las diferencias significativas demostradas en Costa Rica entre los portadores de $\mathrm{HbC}$ de ambos litorales, que una parte importante de la población negra del Atlántico provenía de zonas con una alta prevalencia del haplotipo Ben y $\mathrm{HbC}$, como se observa en Benín, Côte d'Ivoire y los territorios circundantes. Por otra parte, una buena proporción de los ancestros africanos que llegaron a la zona norte del litoral pacífico (provincia de Guanacaste) eran originarios de lugares con una baja frecuencia de $\mathrm{HbC}$ y una alta incidencia del haplotipo CAR. Estas son condiciones genéticas heterocigóticas que se concentran en zonas como Angola, el sur del Gabón, la República Centroafricana y el Zaire $(33,34)$ (cuadro 2). Los datos obtenidos en otras partes de las Américas, África y Europa figuran en el cuadro $3(6,12,26,36)$.

\section{RELACIÓN ENTRE HAPLOTIPOS $\beta^{s}$ Y LAS MANIFESTACIONES CLÍNICAS DE LA DREPANOCITOSIS}

Las manifestaciones clínicas de la anemia drepanocítica clásica han sido bien definidas desde hace mucho tiempo $(1,2,17)$ y se han caracterizado por un conjunto de signos y síntomas propios de una anemia hemolítica crónica grave, con incremento de la susceptibilidad a las infecciones, retraso del crecimiento y desarrollo, crisis de dolor por oclusión vascular, cuadro torácico agudo, síndrome de secuestro esplénico, daño tisular, trastornos del sistema nervioso central, crisis aplásicas y hemolíticas y asplenia funcional $(1,2)$. Existe, sin embargo, gran variabilidad en las manifestaciones hemato-
CUADRO 3. Prevalencia (por 100 habitantes) de haplotipos $\beta^{s}$ en diversas zonas geográficas

\begin{tabular}{ll}
\hline \multicolumn{1}{c}{ Zona } & Haplotipo $(\%)$ \\
\hline África & \\
Argelia & Ben $(100)$ \\
Benín & Ben $(100)$ \\
Kenya & CAR $(98,3)$ \\
Nigeria & Ben $(97,1)$ \\
Senegal & Sen $(83)$ \\
& Ben $(14)$ \\
& CAR $(1,8)$ \\
Europa y Asia & \\
Grecia & Ben $(>90)$ \\
Arabia Saudita & Árabe $(100)$ \\
India (Este) & Árabe $(90)$ \\
& Indio $(8,6)$ \\
Portugal & CAR $(43,8)$ \\
& Sen $(25)$ \\
Sicilia & Ben $(12,5)$ \\
Las Américas & Ben $(>90)$ \\
Antillas Neerlandesas & Ben $(52)$ \\
& CAR $(36)$ \\
Estados Unidos & Sen $(4)$ \\
& Ben $(60)$ \\
Carolina del Sur & CAR $(25)$ \\
& Sen $(10)$ \\
Suriname & Sen $(43)$ \\
& CAR $(40)$ \\
& Ben $(17)$ \\
& Ben $(52)$ \\
CAR $(36)$ \\
Sen $(4)$ \\
\hline
\end{tabular}

Fuente: Referencia 12.

lógicas y clínicas de la enfermedad, lo cual afecta a las tasas de morbilidad y mortalidad de los pacientes con este síndrome drepanocítico mayor en diferentes partes del mundo $(7,29,37)$.

No es fácil explicar esta gama compleja de manifestaciones clínicas. Pueden contribuir a ella ciertos factores ambientales (presencia de malaria, tipo de nutrición, disponibilidad de servicios médicos), como también algunas propiedades del eritrocito anormal, como serían las concentraciones de $\mathrm{Hb}$ fetal; la herencia conjunta de genes $\alpha$-talasémicos o de otras hemoglobinas anormales de tipo silencioso; las concentraciones de 2, 3-difosfoglicerato (2,3-DPG) y, particularmente, la expresión de los diversos haplotipos del gen $\beta^{\mathrm{s}}(2,7,31,37-43)$. En este sentido, los polimorfismos $\beta^{\mathrm{s}}$ 
han cobrado especial importancia en los últimos años, al asociarse su expresión con la gravedad clínica de la enfermedad homocigótica. De tal suerte, al incrementarse el número de pacientes drepanocíticos que alcanzan la edad adulta, no solo debido a las mejores condiciones sanitarias y a la medicina preventiva (44), se ha venido aclarando cada vez más la relación entre estos factores genéticos y las manifestaciones hematológicas y sistémicas de la drepanocitosis $(7,11,44,45)$. Se ha observado que el principal beneficio conferido por algunos de estos haplotipos en relación con la gravedad de la drepanocitosis se explica en términos de su relación directa con las concentraciones sintéticas de $\mathrm{Hb}$ fetal, que suele considerarse "antifalciforme" porque no copolimeriza con la $\mathrm{HbS}$, a la que torna más soluble. En pocos campos de la medicina molecular se palpa mayor interés por estudiar los factores responsables del control sintético de la hemoglobina fetal $(\mathrm{HbF})$ y sus posibilidades terapéuticas que en el del tratamiento de la anemia drepanocítica $(11,37,41,46)$. Además de estimular una mayor o menor síntesis de $\mathrm{HbF}$, los diferentes polimorfismos del gen de la $\mathrm{HbS}$ modifican la proporción de las cadenas $\mathrm{G} \gamma$ y A $\gamma$ de la $\mathrm{HbF}$ en el adulto drepanocítico $(11,35,37)$. En el neonato y en el niño de pocos meses hay más cadenas $\mathrm{G} \gamma$ que cadenas Ay (razón 6:4). En la medida en que se inactiva la síntesis de $\mathrm{HbF}$ en años posteriores, se activa un mecanismo genético que favorece un descenso más acelerado de la producción de cadenas $\mathrm{G} \gamma$ en relación con cadenas A $\gamma(7,37)$, por lo que después del cuarto o quinto mes de edad la razón Gy:A $\gamma$ empieza a ser 4:6, como en el adulto (7). Ya que ciertos haplotipos modulan genéticamente una elevada síntesis de $\mathrm{HbF}$ con un mantenimiento paralelo de la relación G $\gamma$ :A $\gamma$ neonatal, estos suelen aportar un notable beneficio para el paciente enfermo $(7,11,45)$, aunque su valor pronóstico puede variar en cada individuo.

En zonas de las Américas pobladas por habitantes de raza negra, los haplotipos africanos Sen, Ben y CAR son los que predominan, mientras que el haplotipo Cam se encuentra en zonas limitadas $(12,24)$. Los haplotipos Sen, árabe-saudí y asiático se asocian con concentraciones altas de $\mathrm{HbF}$ y con la conservación de la razón $\mathrm{G} \gamma$ : A $\gamma$ del período neonatal normal, 6:4 (7, $31,37)$. Estos polimorfismos genómicos son muy similares entre sí, ya que difieren únicamente en tres sitios de restricción $(6,11)$. Debido a su asociación con el predominio de cadenas $\mathrm{G} \gamma$, cursan con concentraciones altas de $\mathrm{HbF}$, alcanzándose porcentajes de $20 \%$ o más cuando se heredan de forma homocigótica $(7,45)$. Hay pruebas de que el incremento de las concentraciones de $\mathrm{HbF}$ en los haplotipos inocuos Senegal y árabe-saudí e indio está relacionado con la mutación de C a $\mathrm{T}$ en la posición -158 de la región promotora del gen de la hemoglobina G $\gamma$. La herencia del haplotipo CAR o bantú se vincula, por el contrario, con concentraciones de $\mathrm{HbF}$ menores de $5 \%$ y con una razón de $\mathrm{G} \gamma$ :A $\gamma$ muy baja $(7,45)$. Finalmente, los haplotipos Ben y Cam se relacionan con concentraciones intermedias de $\mathrm{HbF}$ (5 a 15\%), con una razón $\mathrm{G} \gamma: A \gamma$ de 1:1 en el haplotipo Ben y con una razón $\mathrm{G} \gamma$ :A $\gamma$ en el haplotipo Cam $(7,11,45)$.

Las repercusiones clínicas de la herencia de estas secuencias polimórficas de ADN se pueden resumir de la siguiente manera: la herencia de un cromosoma CAR, como mínimo, está ligada a cuadros drepanocíticos más graves que los relacionados con la presencia del haplotipo Ben, y este a su vez se asocia con un trastorno más grave que los haplotipos Sen o arábesaudí (11). Un paciente drepanocítico que hereda un cromosoma CAR presentará algún tipo de daño permanente en por lo menos uno de sus órganos vitales durante los primeros cuatro decenios de la vida (11). El haplotipo Sen, por su parte, se vincula con un menor número de episodios "drepanocitémicos", de síndrome torácico agudo y de infarto esplénico y óseo. También se asocia con un menor riesgo de priapismo, necrosis papilar renal, enfermedad pulmonar crónica, glomerulonecrosis, ulceraciones, crisis de secuestro esplénico, infarto óseo y dactilitis. Este curso clínico más ino- cuo también es característico de pacientes que heredan los haplotipos árabe-saudí o asiático $(29,37,45)$.

Por otra parte, el haplotipo Ben se relaciona con un cuadro clínico de gravedad intermedia. Las principales complicaciones halladas en adultos e individuos jóvenes con este marcador son la uremia y la insuficiencia o disfunción de órganos importantes, tales como cerebro, riñón e hígado. De estos pacientes, $90 \%$ presentan crisis de osteonecrosis importantes después de los 20 o 25 años de edad $(37,45)$. Finalmente, en el caso del haplotipo Cam, que es el menos común en África y, por ende, en las Américas, la repercusión sistémica en pacientes con drepanocitosis no está bien definida $(24,37,45)$.

Otro factor que influye en la tasa de morbilidad por anemia drepanocítica es la relación entre el rasgo de $\alpha$-talasemia $(\alpha$-tal) y las diferentes clases de haplotipos $\beta^{\mathrm{s}}(8,40,42,45)$. En general se ha demostrado que la presencia simultánea de $\alpha$-tal atenúa la enfermedad por HbSS (cuadro 4) (8). Los pacientes drepanocíticos que coheredan $\alpha$-tal muestran una supervivencia aumentada de células sin $\mathrm{HbF}$ debido a una disminución de la concentración de $\mathrm{Hb}$ corpuscular media (CHCM) y a un menor grado de hemólisis, con el consiguiente incremento de las concentraciones de $\mathrm{Hb}$ y del hematócrito y con reticulosis más leves (8). No obstante, y a pesar del efecto beneficioso sobre la anemia, la repercusión sobre otras manifestaciones clínicas de la drepanocitosis no es tan clara. Los datos obtenidos hasta el presente parecen indicar que los genes $\alpha$-tal-2 ejercen un efecto protector contra daño tisular irreversible, mecanismo que está presente cuando se hereda simultáneamente un cromosoma Sen o Ben, en tanto que la expresión de un cromosoma CAR parece incrementar el riesgo de este trastorno (45). En cambio, al heredarse simultáneamente $\alpha$-tal-2 y cualquiera de los polimorfismos $\beta^{\mathrm{s}}$ se aumenta de forma significativa el riesgo de osteonecrosis, principalmente si el individuo con $\mathrm{HbSS}$ presenta la combinación Sen/Ben. Este riesgo disminuye ligeramente si los haplotipos asociados son CAR/Ben o 
CUADRO 4. Datos hematológicos (promedios) de 200 pacientes drepanocíticos, homocigóticos para el haplotipo $\beta^{s}$ Benín, con diferente genoma de globina $\alpha$

\begin{tabular}{ccccccccc}
\hline $\begin{array}{c}\text { Genes } \alpha \\
\text { (No.) }\end{array}$ & $\begin{array}{c}\text { Pacientes } \\
\text { (No.) }\end{array}$ & $\begin{array}{c}\text { Edad } \\
\text { (años) }\end{array}$ & $\begin{array}{c}\mathrm{Hb} \\
\mathrm{g} / \mathrm{dL}\end{array}$ & $\begin{array}{c}\mathrm{GR} \\
10^{12} / \mathrm{L}\end{array}$ & $\begin{array}{c}\mathrm{VCM} \\
\mathrm{fl}\end{array}$ & $\begin{array}{c}\mathrm{HCM} \\
\mathrm{pg}\end{array}$ & $\begin{array}{c}\mathrm{HbA}_{\mathrm{s}} \\
(\%)\end{array}$ & $\begin{array}{c}\mathrm{HbF} \\
(\%)\end{array}$ \\
\hline 4 & 123 & 9,5 & 7,4 & 2,59 & 108,7 & 28,8 & 2,8 & 9,5 \\
3 & 82 & 9,5 & 7,8 & 2,97 & 98,6 & 26,3 & 3,1 & 9,1 \\
2 & 15 & 12,8 & 8,2 & 3,76 & 85,7 & 21,3 & 3,6 & 7,6 \\
\hline
\end{tabular}

Fuente: Referencia 8.

Nota: $\mathrm{Hb}$ = hemoglobina; $\mathrm{GR}$ = glóbulos rojos; $\mathrm{VCM}=$ volumen corpuscular medio; $\mathrm{HCM}=$ hemoglobina corpuscular media; $\mathrm{HbA}_{\mathrm{s}}=$ hemoglobina $\mathrm{A}_{\mathrm{s}} ; \mathrm{HbF}=$ hemoglobina fetal.

Ben/Ben $(8,11,37,45)$. A manera de recapitulación, se puede afirmar que pese al efecto deletéreo asociado con la osteonecrosis, se observa una morbilidad más grave en pacientes drepanocíticos con haplotipos CAR o Ben y genoma $\alpha$, al compararlos con pacientes que coheredan el tipo $\alpha$-tal-2 $(8,11$, $37,38)$.

Una valoración inicial de las características clínicas de la drepanocitosis en Costa Rica permite explicar por qué sus manifestaciones clínicas son especialmente graves en la zona de Guanacaste (litoral pacífico), donde la población negroide posee con mayor frecuencia los haplotipos CAR y Ben perjudiciales, y por qué se observan menos complicaciones en pacientes de raza negra del litoral atlántico (Limón), donde el haplotipo "inocuo" Sen se encuentra en hasta $20 \%$ de la población.

\section{CONCLUSIONES}

La relación entre los diversos haplotipos del gen $\beta^{s}$ y los síntomas heterogéneos de anemia drepanocítica ha permitido elucidar, aunque tan solo parcialmente, la expresividad biológica de esta enfermedad, que debe ser debidamente diagnosticada con técnicas apropiadas para descartar otros factores capaces de enmascarar el verdadero genotipo hemoglobínico del paciente. La variabilidad de las mani- festaciones clínicas de la drepanocitosis puede deberse, entre otros factores, a concentraciones aumentadas de $\mathrm{HbF}$; a otras mutaciones ligadas, tales como sitios polimórficos en el cromosoma que posee la mutación $\beta^{\text {s }}$ (haplotipos); a la coexistencia del rasgo de $\alpha$-tal y a factores ambientales. En el caso particular de los sitios polimórficos, la herencia de los haplotipos Sen, árabesaudí o indio se correlaciona con un cuadro clínico menos grave en comparación con el que se asocia con los polimorfismos CAR, Cam o Ben. De los últimos, el CAR o bantú es el implicado en la anemia drepanocítica más grave, posiblemente debido a la menor síntesis de $\mathrm{HbF}$ (menos de $12 \%$ ) y a la persistencia de la razón sintética $\mathrm{G} \gamma: \mathrm{A} \gamma$ del tipo adulto. La caracterización de estos polimorfismos del ADN ha cobrado gran importancia por su utilidad como marcadores genético-antropológicos y, en las Américas especialmente, está ayudando a descifrar las raíces que vinculan a los americanos de raza negra con sus ancestros africanos. En este sentido se ha demostrado la variabilidad genética existente entre las poblaciones negras de los diversos países de las Américas e incluso, como en el caso de Costa Rica, entre diferentes puntos de un mismo país.

\section{REFERENCIAS}

1. Wainscoat JS. The haemoglobinopathies. En: Hoffbrand AV, Lewis SM. Postgraduate haematology, 3a ed. London: Heinman Medical Books; 1989:121-144.

2. Rodgers GP, Schetcher AN. Molecular pathology of the hemoglobin structure. En: Hoffman R, Benz E, Shattil S, Fume B, Cohen H. Haematology: basic principles and practice. New York: Churchill-Livingstone; 1991:441-470.

3. Steimberg MH. DNA diagnosis for the detection of sickle hemoglobinopathies. Am J Hematol 1993;43:110-115.

4. Zhang YH, McCabe L, Wilborn M, Therrell B, McCabe ER. Application of molecular genetics in public health: improved follow-up in a neonatal hemoglobinopathy screening program. Biochem Med Metab Biol 1994;52: 27-35.

5. Nieves MA, López MA, De Pablos, JM Garrido F. La reacción en cadena de la polimerasa: aplicación al estudio de la patología del gen $\beta$ de globina. Biol Clin Hematol 1990;12:121-126.
6. Nagel RL, Ranney HM. Genetic epidemiology of structural mutations of the $\beta$ gene. Semin Hematol 1990;27:324-359.

7. Nagel RL. Severity, pathobiology, epistatic effects, and genetic markers in sickle cell anemia. Semin Haematol 1991;28:180-201.

8. Adekile AD. Factors associated with the distribution and severity of sickle cell disease in Africa. Sphere 1994;17:1-5.

9. Polimorfismos del ADN. En: Colombo B, Svarch E, Martínez G. Genética y clínica de las hemoglobinas humanas. La Habana: Pueblo y Educación; 1993.

10. Kan YW, Dozy AM. Evolution of the hemoglobin $S$ and $C$ genes in world populations. Science 1980;209:388-391.

11. Powars DR. Sickle cell anemia: $\beta^{\mathrm{s}}$-genecluster haplotypes as prognostic indicators of vital organ failure. Semin Hematol 1991;28: 202-208.

12. Schroeder WA, Munger ES, Powars DR. Sickle cell anemia, genetic variations and the trade to the United States. I African History 1990;31:163-180.

13. Fullerton SM, Harding RM, Boyce AJ, Cleggs JB. Molecular and population genetic analysis of allelic sequence diversity at the human $\beta$ globin locus. Proc Nat Acad Sci USA 1994;91: 1805-1809.

14. Flint J, Harding R, Clegg J, Boyce A. Why are some genetic diseases common? Human Genet 1993;91:101-117.

15. Nagel RL. Sickle cell anemia is a multigene disease. Amer J Hematol 1993;42:96-101.

16. Chelboune Y, Pagnier J, Trabuchet G. Structural analysis of the $5^{\prime}$ flanking region of the $\beta$-globin gene in African sickle cell anemia patients: further evidence for three origins of the sickle mutation in Africa. Proc Nat Acad Sci USA. 1988;85:4431-4435.

17. The geographical distribution of the common abnormal $\mathrm{Hb}$ variants. En: Lehman $\mathrm{H}$, Huntsman RG. Man's haemoglobins, 2a ed. Philadelphia: JB Lippincott; 1974:301-310. 
18. Fischman J. Putting our oldest ancestors in their proper place. Science 1994;265:2011.

19. Steimberg MH, Adams III JG. Hemoglobin $\mathrm{A}_{\mathrm{g}}$ : origin, evolution, and aftermath. Blood 1991;78:2165-2172.

20. Livingstone FB. Anthropological aspects of the distributions of the human hemoglobin variants. En: Winter WP, ed. Hemoglobin variants in human populations. Boca Raton, Florida: CRC Press; 1986:17-28.

21. Karazian HH, Waber PG, Boehm CD. Hemoglobin $\mathrm{E}$ in Europeans: further evidence for multiple origins in the $\beta^{\mathrm{E}}$ globin gene. Am J Hum Genet 1984;36:212-217.

22. Antonarakis SE. Evidence for multiple origin of the $\beta^{\mathrm{E}}$ gene in Southeast Asia. Proc Nat Acad Sci (USA) 1982;79:608-615.

23. Boehm C. Evidence supporting a single origin of the $\beta^{\mathrm{c}}$ gene in blacks. Am J Hum Genet 1985; 37:771.

24. Lapoumeroulie C, Dunda O, Trabuchet G, Mony M. Bodo JM, Carnevale P, et al. A novel sickle cell gene of yet another origin in Africa: the Cameroon type. Hum Genet 1992;89: 333-337.

25. Adekile AD. Anthropology of the $\beta^{\mathrm{s}}$-gene flow from West Africa to North Africa, the Mediterranean, and Southern Europe. Hemoglobin 1992;16:105-112.

26. Auloch JR, Kiline Y, Aksoy M, Yuregir GT, Bakiouglu T, Kutlar A, Kutlar F, Huisman THJ. Sickle cell anemia among Eti-turks. $\mathrm{Br} \mathrm{J}$ Haematol 1986;64:45-55.

27. Miller B, Olivier N, Salameh M, Ahmed M, Antognetti G, Huisman THJ. Molecular analysis of the high hemoglobin-F phenotype in Saudi-Arabian with sickle cell anemia. $N$ Engl J Med 1987;316:244-256.

28. Pagnier J, Mears JG, Dunda O, Schaeffer-Rego K, Beldjord C, Nagel RL, et al. Evidence for the multicentric origin of the sickle cell hemoglobin gene in Africa. Proc Nat Acad Sci (USA) 1984;81:1170-1773.
29. Bakioglu I, Hattore $Y$, Kutlar A. Five adults with mild sickle cell anemia shared a $\beta^{\mathrm{s}}$ chromosome with the same haplotype. Am J Hematol 1985;20:297-300.

30. Wainscoat JS, Thein SL, Higgs DR. A genetic marker for elevated levels of haemoglobin $\mathrm{F}$ in homozygous sickle cell disease? Br J Haematol 1985;60:261-268.

31. El-Mouzan M, Al Awang B, Al Torki M. Clinical features of sickle cell disease in eastern Saudi Arab children. Am J Ped Hematol Oncol 1990;12:51-55.

32. Labie D, Srinvas R, Dunda O. Haplotypes in tribal bearing the sickle gene: evidence for the unicentric origin of the $\beta^{\mathrm{s}}$ mutation and the unicentric origin of tribal populations in India. Hum Biol 1989;61:479-491.

33. Sáenz GF. Hemoglobinopatías en los países de la Cuenca del Caribe. Rev Biol Trop 1988; 36:361-372.

34. Sáenz GF, Chaves MA, Quintana E. Las hemoglobinopatías en Costa Rica: aspectos históricos, culturales y epidemiológicos. Rev Costarricense Cien Med 1989;7:95-106.

35. Rodríguez WE, Sáenz GF, Josafovska O, Nagel RL. The African ports of origin of individuals of African descent in Costa Rica: the use of $\beta^{\mathrm{s}}$-gene cluster haplotypes. Rev Invest Clin 1994;April(supl): 245

36. Antonarakis SE, Boehm CD, Serjeant GR, Theisen CE, Dover GJ, Kazazian HH. Origin of $\beta^{\text {s }}$ globin gene in blacks: the contribution of recurrent mutation or gene conversion or both. Proc Nat Acad Sci (USA) 1984;81:853-856

37. Powars D, Chan L, Schroeder WA. The variable expression of sickle cell disease is genetically determined. Sem Hematol 1990;27: 360-370.

38. Mears JG, Lachman HM, Labie D. $\alpha$ thalassemia is related to prolonged survival in sickle cell anemia. Blood 1983;68:286-290.

39. Embury SH, Clark MR, Monroy G, Mohandas N. Concurrent sickle cell anemia and $\alpha$ - thalassemia: effect on pathological properties of sickle erythrocytes. J Clin Invest 1984;73: 116-123.

40. Owang PJ, Ogada T, Beris P, Hattori Y, Lanclor KD. Haplotypes and $\alpha$ globin gene analyses in sickle cell anaemia in patients from Kenya. Br J Haematol 1987;65:211-215.

41. Rodgers GP, Dover G, Uyesaka N, Nboguchi C, Schetcher A, Nienhus A. Augmentation of erythropoietin of the fetal hemoglobin response to hydroxyurea in sickle cell disease. $N$ Engl J Med 1993;328:73-80.

42. Schroeder WA, Powars DR, Kay L. $\beta$ cluster haplotypes, $\alpha$ gene status and hematological data from SS, SC and $S / \beta$ thal patients in southern California. Hemoglobin 1989;13: 325-353.

43. Steimberg MH. The interaction of $\alpha$ thalassemia with hemoglobinopathies. Hematol Oncol Clin N Am 1991;5:453-467.

44. Sáenz GF, Chaves M, Rodríguez W, Sánchez G, Barrantes A, Barrenechea M, et al. Frecuencia de $\beta$ tal y otras hemoglobinopatías en población costarricense de raza negra. Rev Costarricense Cien Med 1990;11:3-10.

45. Powars DR. $\beta^{\text {s}}$-gene-cluster haplotypes in sickle cell anemia. Hematol Oncol Clin N Am 1991;5:475-493.

46. Powars D, Chan L, Schroeder WA. The variable expression of sickle cell disease is genetically determined. Hematol Oncol Clin N Amer 1990;27:360-370.

Manuscrito recibido el 30 de abril de 1996 y aceptado para publicación en versión revisada el 17 de julio de 1997.
ABSTRACT

\section{S hemoglobin haplotypes: their epidemiologic, anthropologic, and clinical significance}

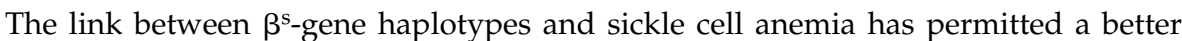
understanding of the biological manifestations of this disease. The use of better laboratory methods can help rule out other hereditary factors that can camouflage the real hemoglobin genotype. The clinical heterogeneity of sickle cell disease, which is characterized by the presence of $S$ hemoglobin, can be explained in terms of fetal hemoglobin $(\mathrm{HbF})$ levels, ratio of $\mathrm{G} \gamma$ chains to $\mathrm{A} \gamma$ chains, 2,3-diphosphoglycerate levels, linked mutations, $\beta^{\text {s }}$ haplotypes, coexistence of $\alpha$-thalassemia, and environmental factors. The inheritance of Sen and Arab/Indian $\beta$-gene cluster polymorphisms is associated with a milder clinical course, whereas the Central African Republic (CAR) or Bantu, Cameroon, and Benin haplotypes are linked with severe sickle cell disease. The CAR haplotype carries the worst prognosis of all (less than $12 \% \mathrm{HbF}$ levels and adulttype $\mathrm{G} \gamma$ :A $\gamma$ ratio).

Once characterized, these DNA polymorphisms also assume great importance as anthropologic and genetic markers. In America, $\beta^{\text {s }}$ haplotypes are contributing to a better understanding of Black American roots and their African ancestry. There is ample evidence of genetic variability not only between different Black populations in America, but also within the same country, as is the case in Costa Rica. 